\title{
Parental care and breeding strategies of the Jacky Winter and its life-history traits compared with other Australasian robins, and northern temperate and tropical songbirds
}

\author{
Richard H. Donaghey, 2* and Carolyn A. Donaghey² \\ 'Environmental Futures Research Institute, Griffith University, Nathan 4111 QLD, Australia \\ 280 Sawards Road, Myalla TAS 7325, Australia \\ ${ }^{*}$ Corresponding author. Email: ricardo@southernphone.com.au
}

\begin{abstract}
We studied parental care in the Jacky Winter Microeca fascinans at Gluepot Reserve, South Australia, for one breeding season from 16 August to 9 November 2001, supplemented by observations on breeding and social behaviour in September 2012. We monitored ten nests in 2001, nine of which were attended by pairs and one by three adults, and watched three nests for a total of c. 117 hours. Female incubation constancy was 69\%, duration of incubation sessions averaged 4.58 minutes and absences from the nest 2.07 minutes. Mean number of nest visits per hour by two pairs during the incubation period was 10.6 and for a group of three adults (two males, one female) was 15.8. Female care included brooding, feeding of nestlings, and nest-hygiene. Male care included delivering food to the sitting female, feeding the nestlings, nest-hygiene, nest-defence, and territoriality. Mean female brooding constancy was $55 \%$. Mean number of feeding trips per hour by male and female combined for the entire nestling period was 14.6. Older young, 12, 13 and 14 days of age, received 21,20, and 29 feeds/h respectively or one feed about every 2 minutes. Mean number of visits per hour by male and female combined to a nest with two young was 16.5 for Days 1-10 and 20.4 for Days 11-18 of the nestling period. High nest-predation is discussed in relation to nest placement and concealment, high nest visitation during incubation and nestling stages, anti-predator behaviour, nest-defence and types of predators, and re-nesting capacity, and compared with other Australasian robins and northern temperate and tropical songbirds. The small nest, small clutch-size, high nest failure, and anti-predator posture and mottled plumage of nestlings suggest that nest-predation is a strong selective pressure in the Jacky Winter. However, the moderately long nestling period, brood-size reduction, high rates of feeding young and nest visits by both male and female, and short and frequent incubation and brooding bouts on and off the nest relative to other robins are not consistent with nest-predation theory, and suggest behavioural responses to food availability and an ultimate response to food limitation. Incubation behaviour on and off the nest, parental care of young, nest visitation and other life-history traits that influence reproductive effort are discussed to elucidate the breeding strategy compared with other Australasian robins.
\end{abstract}

\section{Introduction}

The Jacky Winter Microeca fascinans is a small (15 g), flycatcher-like, ground-pouncing and aerial insectivorous Australasian robin (Petroicidae: Subfamily Microecinae) (Recher et al. 2002; Loynes et al. 2009; Christidis et al. 2011) that occurs throughout Australian woodlands, open forests and mallee (Higgins \& Peter 2002; Boles 2007). This paper follows the taxonomy of Beehler \& Pratt (2016) for flyrobins endemic to New Guinea, but follows Christidis \& Boles (2008) in usage of the common name, Lemonbellied Flycatcher, for Microeca flavigaster. Taxonomy and sequence of Australian robins follow Gill \& Donsker (2017). Detailed studies on the breeding biology of Australian robins have been conducted for the Grey-headed Robin Heteromyias cinereifrons (Frith \& Frith 2000), Eastern Yellow Robin Eopsaltria australis (Marchant 1985a; Zanette 2000; Zanette et al. 2000; Berry 2001; Debus 2006a), White-breasted Robin E. georgiana (Russell et al. 2004a), Hooded Robin Melanodryas cucullata (Fitri \& Ford 2003; Debus 2013), Flame Robin Petroica phoenicea (Robinson 1990), Scarlet Robin P. boodang (Robinson 1990; Debus 2006a), Red-capped Robin P. goodenovii (Dowling 2003; Powys 2004), and Southern Scrub-robin Drymodes brunneopygia (Brooker 2001). The breeding biology of the Jacky Winter is reasonably well known (Higgins \& Peter 2002), and breeding territories and breeding success have been documented (Wood et al. 2008). Our study presents the first detailed account of parental care in a microecine robin.

Our study is important for two main reasons. First, field studies of Australian robins advance our knowledge and understanding of life-history traits of 'Old Endemic' southern temperate songbirds and seek to explain variation and patterns among southern temperate passerines compared with those from tropical and northern temperate regions. We conducted an intensive study of parental care in the Jacky Winter to help elucidate the selective forces that shape the strategy of parental care in this species and identify any constraints to reproductive effort such as nest-site characteristics, incubation behaviour, care of nestlings and nest-predation. Second, the Jacky Winter is a ground-foraging, woodland bird that is declining throughout southern Australia and thus is of conservation concern (Barrett et al. 2003; Olsen et al. 2005; Watson 2011). Ground-foraging birds represent a considerable proportion of declining woodland birds (Antos \& Bennett 2006; Ford 2011). Across their range in south-western and south-eastern Australia, Jacky Winters forage mainly by pouncing from a perch to the ground to capture invertebrates but also take prey aerially (hawking) and by snatching prey from a substrate. In Wandoo Eucalyptus wandoo woodlands in south-western Australia, the most important foraging substrates used by Jacky Winters were ground (66\%) and air (26\%) (Recher \& Davis 1998), and in temperate woodlands of northern Victoria they were 
ground-litter (49\%), bare ground (20\%) and air (12\%) (Antos \& Bennett 2006). Further understanding of social organisation, foraging and nesting habitat requirements, life-history attributes and constraints to reproductive effort can contribute to more effective conservation management for the Jacky Winter.

The main objectives of this study were to document: (1) social organisation; (2) daylight incubation constancy, the number of nest visits and the duration of on- and off-bouts during incubation; (3) brooding constancy and the number of food-delivery trips to the nest throughout the nestling period; (4) nest success, nest failure, antipredator behaviour of adults and young, and potential nest-predators; and (5) to compare all these traits with coexisting (Red-capped and Hooded Robins and Southern Scrub-robin) and other robin species.

\section{Study site and methods}

Parental care of the Jacky Winter was studied from 16 August to 9 November 2001 at Gluepot Reserve, South Australia $\left(33^{\circ} 45^{\prime} \mathrm{S}, 140^{\circ} 7^{\prime} \mathrm{E}\right)$, elevation $57 \mathrm{~m}$ above sealevel (asl). Supplementary observations of breeding and social behaviour and organisation of this species were made there in September 2012.

Gluepot Reserve (54 390 ha) is part of the 9000-km² Riverland Biosphere Reserve (formerly named Bookmark Biosphere Reserve) that protects the largest area of intact mallee in southern Australia (Mackenzie \& Fitzsimons 2013). At Gluepot Reserve from 2000 to 2016, the mean annual rainfall was $285 \mathrm{~mm}$ (range $127.9-505.7 \mathrm{~mm}$ ), the mean annual maximum temperature was $25.3^{\circ} \mathrm{C}$, and the mean annual minimum temperature was $9.3^{\circ} \mathrm{C}$. In 2001 , the annual rainfall was $227.4 \mathrm{~mm}$ and rainfall for the months August to November was $121.6 \mathrm{~mm}$ (Bureau of Meteorology, http://www.bom.gov.au). In 2001, the rainfall at Gluepot (weather station 020028) for each season was $27.8 \mathrm{~mm}$ (summer), $29.2 \mathrm{~mm}$ (autumn), $69.7 \mathrm{~mm}$ (winter), and $100.7 \mathrm{~mm}$ (spring), compared with means over the period 2001-2016 of $78 \mathrm{~mm}, 57.4 \mathrm{~mm}, 65.8 \mathrm{~mm}$ and $73.4 \mathrm{~mm}$, in summer, autumn, winter and spring, respectively. Thus, Gluepot had a wetter than average winter and spring in 2001, and mean seasonal rainfall from 2001 to 2016 was highest in spring and summer.

The predominant vegetation association inhabited by Jacky Winters was Acorn Mallee or Oily Mallee Eucalyptus oleosa over shrubs in swales and to a lesser extent Beaked Red Mallee E. socialis over Porcupine Grass Triodia scariosa, and Black Oak Casuarina pauper open forest edge with mallee eucalypts (Hyde 2001). Both E. oleosa and also E. socialis are called Red Mallee (Chippendale 1988; Brooker \& Kleinig 2001). E. socialis is also called Summer Red Mallee or Pointed Mallee (New South Wales Flora Online, http://www.plantnet.rbgsyd. nsw.gov.au). We searched for Jacky Winters around campgrounds, off roads and tracks, and found ten active nests (Nests 1-10). Nests were watched from hides and adults were observed through a $25 \times$ telescope. To determine the time that Jacky Winters spent incubating, we conducted three 12-hr watches at three nests during the late incubation period for 2150 minutes (35.83 h). In this study, nest-attentiveness is the total number of minutes spent incubating by a female Jacky Winter during a defined period of daylight. Incubation constancy is the percentage of hours of daylight spent in incubation. The duration of all bouts on and off the nest were timed to the nearest second with a lap/split stop-watch. An incubation session or 'on-bout' is the duration of time in minutes and seconds spent at the nest in incubation. An absence or 'off-bout' is the duration of time in minutes and seconds that an incubating female spends away from the nest. Male incubation feeding (feeding of a female by her mate on and off the nest during the incubation period) was recorded during mornings and afternoons at two nests (Nest 2 of a pair and Nest 9 attended by three adults). The time that females spent brooding was determined by watching three nests (Nests 2, 5 and 9), each with a brood-size of two, from $0600 \mathrm{~h}$ to $1800 \mathrm{~h}$ throughout the nestling period for a total of 4862 minutes (81.03 h). Brooding constancy is the percentage of daylight hours that a female spends at the nest brooding young. Nest 2 was watched for 350 minutes $(5.8 \mathrm{~h})$ on only 1 day as the nest was depredated. Nest 9 was observed for 900 minutes (15 h) on Days 1, 4, and 6 of the nestling period, but 2 days later it failed. The third nest (Nest 5) was watched for 3612 minutes $(60.2 \mathrm{~h})$ from Day 1 (the day that the first egg hatched) to fledging of the two young, on Days 19-20, to determine the time spent brooding, the number of feeding trips per hour, and the role of the male and female in the removal of faecal sacs. Up to Day 13 of the nestling period, the female was identified by her brooding and food-solicitation behaviour. During afternoon watches from Days 8-13, when the bird carrying food to the nest did not brood it was not possible to determine the sex of the individual bird. After Day 13 the sex of all adults was unknown. To calculate mean feeding rates for each half of the nestling period, we first averaged feeding rates for all nest-watches for a particular day of the nestling period, and then averaged all those means. Antipredator behaviour, such as nest-defence and predator avoidance, and cryptic behaviour by nestlings, were recorded. Nest success is the proportion of nests in which eggs are laid and young fledge. Heights of all nests above the ground were measured and nest-site characteristics were recorded after the end of nesting.

\section{Results}

\section{Observations of breeding system and social behaviour}

Jacky Winters are socially monogamous, territorial pairbreeders (Higgins \& Peter 2002; Wood et al. 2008). We observed cooperative breeding in Jacky Winters once in 2001 at Gluepot Reserve when two adults (presumably both males) fed the incubating female, and also fed the brooding female, which then fed the young (R. Donaghey in Higgins \& Peter 2002; RHD \& CAD pers. obs.).

From 1 to 7 September 2012 at Gluepot Reserve, RHD recorded the social, foraging, and breeding behaviour in nine Jacky Winter territories, six of which were occupied by a pair of Jacky Winters. In one territory at $0715 \mathrm{~h}$ on 4 September, RHD watched a synchronised sexual display flight of two Jacky Winters fluttering their wings and with tails fanned while hovering $\sim 50 \mathrm{~m}$ above the ground. Both birds were $\sim 40 \mathrm{~cm}$ apart, and when the lead bird moved a few centimetres, the other shifted position so that both 
birds remained close. When the lead bird flew further on, the other followed close behind until both were out of sight.

A group of three Jacky Winters was seen together in three of the nine territories. In Territory 9 on 7 September, RHD observed a metal-banded Jacky Winter (presumably the female) building a nest on a dead horizontal fork of a mallee eucalypt. It gathered nest material from the ground and made ten trips to the nest while its mate (presumably engaged in mate-guarding) perched $5 \mathrm{~m}$ from the nest and sang. The third Jacky Winter perched $10 \mathrm{~m}$ away, and once all three birds perched $5-10 \mathrm{~cm}$ apart on the same dead branch $6 \mathrm{~m}$ from the nest. In Territory 3 at $0800 \mathrm{~h}$ on 2 September, RHD watched three Jacky Winters engaged in foraging and social behaviour. Two birds perched together and mutually preened while the third perched on a dead twig $<5 \mathrm{~m}$ away. One of the two closely perched individuals flew off, and the other two followed in an aerial pursuit with no overt antagonism between them. In Territory 7 at 1545-1600 h on 5 September, RHD watched a group of three Jacky Winters foraging together. Initially two of them foraged and perched close to each other while the third was $20 \mathrm{~m}$ away. Several times, all three birds perched together on the same branch after perch-pounce foraging. It was not known if these last two groups of three Jacky Winters stayed together and bred.

\section{Nest initiation}

In 2001, the first Jacky Winter nest was found on 19 August when RHD observed a bird wiping spider web on a nest foundation. Of the ten nests found, two were initiated in August (Nests 1 and 2), five were being built in September (Nests 3-7), and three nests with eggs were found in October. The last nestling fledged on 8 November.

\section{Nest-site characteristics and nest outcome in relation to height of nest above the ground}

All ten Jacky Winter nests in 2001 were built on an exposed horizontal fork of a dead branch, nine in Acorn Mallee and one in Black Oak fringing the mallee eucalypts. Mean nest height above the ground was $2.5 \mathrm{~m}$ (range 1.55-4.25 m). Of five nests that failed (one during construction and four with eggs), three (Nests 1, 3 and 6 ) were $<2 \mathrm{~m}$ and two (Nests 4 and 8 ) were $>2 \mathrm{~m}$ above the ground. Of three nests with nestlings that were depredated, two (Nests 9 and 10 ) were $<2 \mathrm{~m}$ and one (Nest 2) was $>2 \mathrm{~m}$ above the ground. Eggs hatched in half the nests, two of which were $<2 \mathrm{~m}$ and three $>2 \mathrm{~m}$ above the ground. The two nests where young fledged (Nests 5 and 7 ) were $>2 \mathrm{~m}$ above the ground.

\section{Male incubation feeding and female foraging off the nest}

Male incubation feeding (typical breeding behaviour of Australasian robins) was observed when an incubating Jacky Winter solicited food by quivering and elevating her wings and emitting high cheeps and squeaks; in response, the male either flew to the nest and fed her or fed her off the nest. The rates of male incubation feeding per hour for one 6-h morning watch and one 6-h afternoon watch, at a nest of a pair and at a nest attended by two males, are presented in Table 1. At the nest of the pair (Nest 2), the male fed the female on the nest 15 times during the
Table 1. Incubation feeding of Jacky Winters, Gluepot Reserve, South Australia, 2001: number of times that an incubating female was fed at the nest by a male or by two males during a morning and an afternoon nest-watch.

\begin{tabular}{lcc}
\hline Time & $\begin{array}{c}\text { Nest of pair } \\
\text { (Nest 2) }\end{array}$ & $\begin{array}{c}\text { Nest attended by } \\
\text { 2 males (Nest 9) }\end{array}$ \\
\hline Morning & 1 & 6 \\
\hline $0600-0700 \mathrm{~h}$ & 1 & 9 \\
\hline $0700-0800 \mathrm{~h}$ & 4 & 1 \\
\hline $0800-0900 \mathrm{~h}$ & 4 & 14 \\
\hline $0900-1000 \mathrm{~h}$ & 3 & 3 \\
\hline $1000-1100 \mathrm{~h}$ & 2 & 9 \\
\hline $1100-1200 \mathrm{~h}$ & $\mathbf{1 5}$ & $\mathbf{4 2}$ \\
\hline Total & & \\
\hline & & 4 \\
\hline Afternoon & & 10 \\
\hline $1200-1300 \mathrm{~h}$ & 2 & 9 \\
\hline $1300-1400 \mathrm{~h}$ & & 7 \\
\hline $1400-1500 \mathrm{~h}$ & & 2 \\
\hline $1500-1600 \mathrm{~h}$ & & 6 \\
\hline $1600-1700 \mathrm{~h}$ & $\mathbf{3 8}$ \\
\hline $1700-1800 \mathrm{~h}$ & $\mathbf{2}$ & $\mathbf{8 0}$ \\
\hline Total & & \\
\hline $\mathbf{1 2 - h}$ total & & \\
\hline
\end{tabular}

morning (2.5 times/h) and twice during the afternoon (0.3 time/h). At the nest attended by three adults (Nest 9 ), the two males fed the sitting female 42 times during the morning $(7$ times $/ \mathrm{h})$ and 38 times during the afternoon (6.3 times/h). Over a 12-h day, two males fed an incubating female at the nest 6.7 times/h or nearly five times the rate by a single male (1.4 times/h).

At Nest 2 during a 6-h morning watch, the female sallied off the nest six times between $0700 \mathrm{~h}$ and $0800 \mathrm{~h}$ and caught flying insects, and between $0800 \mathrm{~h}$ and $0900 \mathrm{~h}$ she flew off the nest five times to catch insects in the air and on the ground. Between $0900 \mathrm{~h}$ and $1000 \mathrm{~h}$, she flew off the nest once to hawk insects and once pounced to the ground.

\section{Incubation rhythm}

Three Jacky Winter nests (each containing a clutch of two eggs) were watched during the second week of incubation for a combined total of 2150 minutes (Nest 2 for 710 minutes, and Nests 5 and 9 for 720 minutes each). Nest-attentiveness, incubation constancy, and the number and duration of incubation sessions (on-bouts) and absences (off-bouts) by the female at these nests are shown in Appendix 1. Mean incubation constancy for the three females was $69.2 \%$. For the three nests combined, mean incubation session length was 4.58 minutes (range 0.05-56.08 min., $n=325$ ). The mean number of complete incubation sessions was 9 per hour. Mean length of absences from the nest for the three females combined was 2.07 minutes (range 0.02-19.25 min., $n=298$ ). Frequency of nest visits by both male and female for two nests of pairs (Nests 2 and 5) was 8.6/h and 12.6/h respectively, 


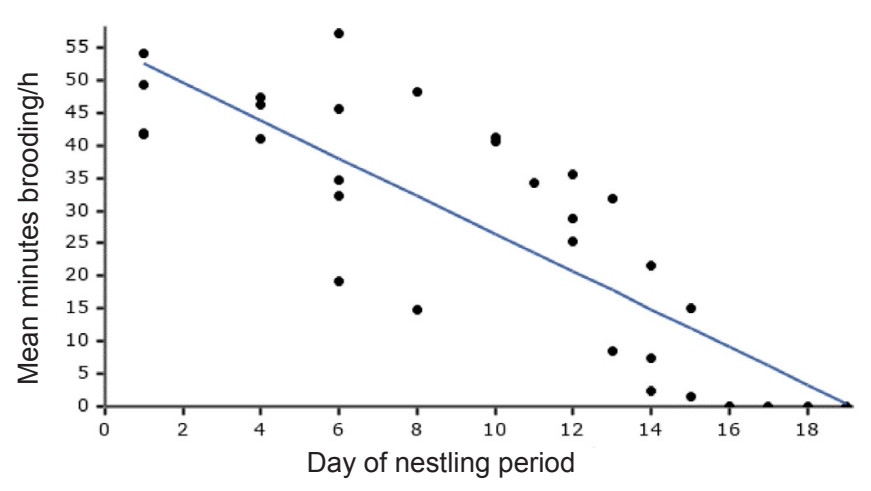

Figure 1. Relationship between daytime brooding by female Jacky Winters and nestling age. Each data point represents the mean minutes brooding per hour for each of 32 nest-watches [mean duration $180.12 \mathrm{~min}$. (range 150-240 min., $n=25$ ) for first 14 days and $51.3 \mathrm{~min}$. (range 10-98 min., $n=7$ ) for next 5 days]. Day 1 of the nestling period represents the day that the first nestling hatched. The linear regression equation is $Y=55.4-2.9 X ; r^{2}=0.7$, $P<0.0001$, significance level $=95 \%$.

whereas the cooperative group (Nest 9) made an average of 15.8 nest visits/h. For four quartiles from $0600 \mathrm{~h}$ to $1800 \mathrm{~h}$, the mean number of visits by the female to and from the nest per hour was 18.0 (range 14.0-19.3) from $0600 \mathrm{~h}$ to $0900 \mathrm{~h}, 20.9$ (range 17.7-26.0) from $0900 \mathrm{~h}$ to $1200 \mathrm{~h}, 23.2$ (range 16.3-36.0) from $1200 \mathrm{~h}$ to $1500 \mathrm{~h}$, and 13.8 (range $4.7-20.0$ ) from $1500 \mathrm{~h}$ to $1800 \mathrm{~h}$. The total number of nest visits by both male and female per 12-h day was 102 and 151 for the two nests of pairs, and 189 for the cooperative group.

\section{Hatching, nestling period and growth of nestlings}

In three nests in which hatching synchrony was observed (Nests 2, 9 and 10), the two young hatched within 24 hours of each other. At the nest where two young fledged (Nest 5), one egg hatched 25-36 hours after the other. The nestling period at one nest (Nest 5) was 19 days. At two accessible nests that were depredated, the young were weighed. At Nest 9, the two young each weighed $1.55 \mathrm{~g}$ on the day of hatching (Day 1), $3.6 \mathrm{~g}$ and $3.8 \mathrm{~g}$ on Day 3, and $5.5 \mathrm{~g}$ and $4.7 \mathrm{~g}$ on Day 5; 2 days later, one weighed $8.4 \mathrm{~g}$ and the other was dead, presumably from starvation. At Nest 10, two young were 1-2 days old when first observed, and 1 day later weighed $3.7 \mathrm{~g}$ and $2.9 \mathrm{~g}$.

\section{Parental care of nestlings}

Three nests (Nests 2, 5 and 9) were watched for a combined total of 2902 minutes $(59.7 \%$ of watches) in the morning and 1960 minutes $(40.3 \%$ of watches) in the afternoon.

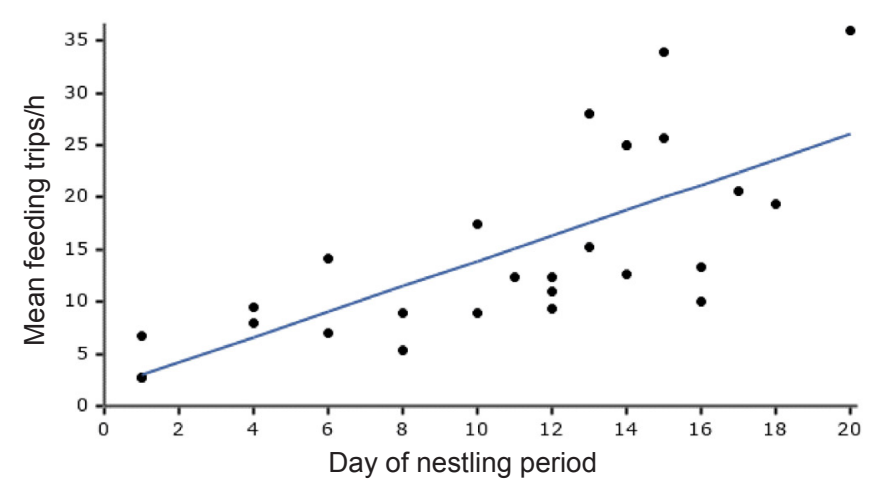

Figure 2. Relationship between Jacky Winter feeding trips and nestling age for a brood of two at one nest (Nest 5). Each of the data points represents the mean number of feeding trips per hour for each of 27 nest-watches [mean duration $162.65 \mathrm{~min}$. (range 60-188 $\mathrm{min}$., $n=20$ ) for first 14 days and $51.3 \mathrm{~min}$. (range 10-98 min., $n=7$ ) for next 5 days]. Day 1 of the nestling period is the day that the first nestling hatched. The linear regression equation is $Y=1.7+1.2 X ; r^{2}=0.5, P<0.0001$, significance level $=95 \%$.

Only the female brooded the young, but the male brought food to the nest and passed it to the brooding female, which either consumed the food or fed the young directly. Time spent brooding varied with ambient temperature, time of day and nestling age. No brooding was observed after Day 15 of the nestling period (Appendix 2). Figure 1 shows a significant inverse linear relationship between time spent brooding and nestling age. Time spent brooding was mostly greater in the cooler mornings and lower in afternoons (12 of 15 data points above the line of best fit were morning watches and eight of 11 below this line were afternoon watches). Brooding declined from $54.2 \mathrm{~min} . / \mathrm{h}$ on the day of hatching (Day 1) to $1.5 \mathrm{~min} . / \mathrm{h}$ on Day 15 (Appendix 2). The time spent brooding on Days 1-10 and Days $11-18$ is shown in Table 2. For the whole nestling period, mean brooding duration was $33.03 \mathrm{~min} . / \mathrm{h}$, and mean brooding constancy was $55 \%$.

Up to Day 13 of the nestling period at the nest where two young fledged (Nest 5), the female was identified by her brooding and food-solicitation behaviour. The male contributed to parental brood care by catching and delivering food to the female, which either consumed the food or passed it to the young. He also fed the young directly, as did the female when she visited the nest carrying food. This complexity in parental care roles is quantified in Appendix 2. The number of feeding trips to the nest varied with time of day and nestling age. Figure 2 shows a significant linear relationship between number of feeding trips to the nest and nestling age. The number of feeding trips per hour per nest-watch increased from 2.7

Table 2. Brooding by female Jacky Winters at three nests (Nests 2, 5 \& 9), Gluepot Reserve, South Australia, 2001: total brooding time, time per hour and constancy (C).

\begin{tabular}{ccccc}
\hline Days of nestling period & Observation time (min.) & \multicolumn{3}{c}{ Brooding } \\
\cline { 3 - 5 } & & Total time $($ min.) & Min./h & C (\%) \\
\hline $1-10$ & 3030 & 2089.1 & 41.37 & 69 \\
\hline $11-18$ & 1832 & 587.5 & 19.21 & 32 \\
\hline $1-18$ & 4862 & 2676.6 & 33.03 & 55 \\
\hline
\end{tabular}


Table 3. Mean numbers of feeding trips and nest visits per hour (ranges in parentheses) at one Jacky Winter nest with two young (Nest 5), Gluepot Reserve, South Australia, 2001.

\begin{tabular}{cccc}
\hline Days of nestling period & Observation time (min.) & Feeding trips/h & Nest visits/h \\
\hline $1-10$ & 1780 & $8.8(4.0-13.2)$ & $16.5(9.0-25.0)$ \\
\hline $11-18$ & 1822 & $18.2(10.8-28.9)$ & $20.4(11.5-34.0)$ \\
\hline $1-18$ & 3602 & $14.6(4.0-28.9)$ & $19.0(9.0-34.0)$ \\
\hline
\end{tabular}

(Day 1) to highs of 34 (Day 15) and 36 (Day 20) (Appendix 2 , Figure 2). Higher feeding rates per hour were recorded in the afternoons on Day 1 (6.7), Day 4 (9.5), Day 6 (14.2), Day 10 (17.5) and Day 13 (28), whereas higher morning feeding rates per hour were observed for Day 8 (27), Day 12 (12.3) and Day 14 (25), possibly reflecting prey availability (Appendix 2). Most data points above the line of best fit are for afternoon watches (Figure 2). Mean number of feeding trips per hour was 8.8 for Days $1-10$ and 18.2 for Days $11-18$ of the nestling period, and 14.6 for the entire nestling period (Table 3 ). Older young, 12, 13 and 14 days of age, received 21, 20 and 29 feeds per hour, respectively, or one feed about every 2 minutes. On the morning just before the second young fledged, it was fed ten times in 6 minutes or one feed every 1.7 minutes. Mean total number of visits to the nest per hour by both male and female for Days $1-10$ of the nestling period was 16.5 , and 20.4 for Days 11-18, excluding a 10-minute watch on Day 20 just before the second young fledged, and 19.0 for the whole nestling period (Table 3).

In addition to feeding of the nestlings, both the male and female assisted in nest-hygiene by removing faecal sacs. The male also alerted the female and young to potential predators and both male and female defended the area around their nest.

\section{Anti-predator behaviour of adults and nestlings}

Anti-predator behaviour includes nest-defence and predator avoidance. In this study, nesting Jacky Winters responded to the presence of nearby large, uncommon potential avian predators such as Collared Sparrowhawk Accipiter cirrocephalus and Grey Currawong Strepera versicolor by darting off the nest and not returning for up to an hour until the predator left. Jacky Winters attack and pursue small to medium-sized birds that intrude into their nest area. During the late incubation period, RHD observed a male Jacky Winter make an attack flight at a male Crested Bellbird Oreoica gutturalis foraging on the ground $5 \mathrm{~m}$ from the nest-tree, and in response the Bellbird flew away. On another occasion, a brooding female Jacky Winter swooped off the nest, and attacked and expelled a male Crested Bellbird foraging on the ground $2 \mathrm{~m}$ away. Twice, a male Jacky Winter flew at and expelled a Yellowplumed Honeyeater Ptilotula ornata near the Jacky Winter nest. Other potential avian predators observed in Jacky Winter territories at Gluepot Reserve include the Grey Shrike-thrush Colluricincla harmonica and Australian Raven Corvus coronoides. During the last half of the nestling period, particularly from Day 13 to fledging, after the two young were fed and ceased comfort behaviour they adopted a cryptic anti-predator posture. During periods when the adult Jacky Winters were absent, the two young sat motionless with their bills pointing upward.
Nest success, nest failure, brood-reduction and productivity

Of the ten nests, one (Nest 3) was partially destroyed and abandoned during construction, four nests with eggs failed (Nests 1, 4, 6 and 8), two young hatched in each of five nests (Nests 2, 5, 7, 9 and 10), and young fledged in two nests (Nests 5 and 7 ). Egg success was $55.6 \%$ (10 of 18 eggs laid in nine nests hatched). Nest success was $22.2 \%$. Two young fledged in one nest (Nest 5 ), and brood-size was reduced to one in another nest when one young disappeared during the first week (Nest 7). Two of nine territories produced a total of three fledglings, a productivity of 0.33 fledgling per pair.

\section{Discussion}

Some Jacky Winter breeding traits that influence reproductive effort are compared below with coexisting and other Australasian robins to try to elucidate the parental care strategy of the Jacky Winter.

\section{Length of breeding season}

An extended breeding season should enable birds to increase reproductive output through more replacement clutches and multiple broods. In the present study in 2001, fieldwork was conducted for 86 days (2.8 months), not long enough to determine the duration of the breeding season. In two studies that documented multiple breeding in the Jacky Winter, in the warm temperate Sydney region of New South Wales (NSW) and in subtropical south-eastern Queensland, the breeding season was c. 4 and 5 months respectively (Keast 1994; Wood et al. 2008). In northwestern Victoria in a wetter region than Gluepot Reserve, multibrooded Red-capped Robins bred during 5 months in each of two seasons, and initiated new nests from August to December (Dowling 2003). In the Northern Tablelands of NSW, the Eastern Yellow Robin laid eggs from mid August to early January (a nesting season of c. 5 months), and the Scarlet Robin laid eggs from mid August to early December (a nesting season of c. 4 months) (Debus $2006 \mathrm{~b})$. In the same region, McLean et al. (2005) found that for a woodland bird community the timing and length of breeding activity varied amongst species in response to rainfall and predator presence. In the mallee region of south-eastern Australia, most birds breed in spring in response to increasing day length (Emison \& Bren 1989; RHD \& CAD pers. obs. at Gluepot). Recher \& Davis (2014) documented declines in abundance and reduced breeding of birds in response to less rain after above-average summer rainfall in the semi-arid Great Western Woodlands, Western Australia. Stevens \& Watson (2013) evaluated the influence of reduced rainfall on declining woodland birds 
over a 21-year period on the north-western slopes of NSW, and attributed decreasing summer-autumn rainfall as the most likely factor driving declines in small insectivorous birds. Reduced summer rainfall reduces soil moisture and thus has the greatest effect on soil- and litter-dwelling invertebrates, the food of ground-foraging birds (Taylor 2008; Watson 2011).

Breeding seasons of passerines in a semi-arid environment such as Gluepot probably vary between 3 and 4 months depending on seasonal rainfall before, and during, breeding, and food availability. Thus, aboveaverage summer rainfall can extend the breeding season of robins through replacement nests after nest failure and nest success and, conversely, reduced rainfall and droughts can shorten the breeding season. Around monsoonal tropical Darwin, Northern Territory, the Lemon-bellied Flycatcher has a biannual breeding season of $c .5$ months, two in the late wet and three in the late dry season (Noske \& Franklin 1999; Noske 2011). In tropical New Guinea, the breeding season extends for 7 months in the lowland Olive Flyrobin Kempiella flavovirescens and montane Papuan Flyrobin Devioeca papuana (Bell 1982; Coates 1990; Donaghey 2017). These few observations of Australasian robins lend support to the notion that passerines in the tropics generally have longer breeding seasons than in temperate latitudes (Ricklefs 1966; Wyndham 1986; Noske \& Franklin 1999; Russell et al. 2004a).

\section{Clutch-size}

Food limitation and nest-predation are significant interacting selection pressures in the evolution of avian clutch-size (Martin 1995). In the present study, the clutchsize of Jacky Winters was two. In Australian robins, clutchsize is one to four (usually two or three but mostly two), and usually three in four Petroica species and the Dusky Robin Melanodryas vittata (Higgins \& Peter 2002). In New Guinean robins, clutch-size is one in montane species, and one or two in lowland species (Donaghey 2015). The mean clutch-size of landbirds is just over two in the tropics and most southern latitudes in Australasia, the Afrotropics and Oceania compared with 4.5 in northern latitudes (Jetz et al. 2008).

\section{Incubation and nestling periods}

In this study, the Jacky Winter's incubation period of c. 17 days falls within the range of 16-19 days (Higgins \& Peter 2002). This is longer than the mean of 14 days in the
Red-capped Robin (Dowling 2003) but similar to the Greyheaded Robin (17-19 days: Frith \& Frith 2000), Lemonbellied Flycatcher (c. 18 days: Noske 2011), and five New Zealand robins (17-22 days: Higgins \& Peter 2002).

The Jacky Winter nestling period of 19 days in this study is more similar to that in the Lemon-bellied Flycatcher (18-21 days) and the longer nestling periods of some New Zealand robins (17-22 days, usually 18 days: Higgins \& Peter 2002) than those in the Southern Scrub-robin (9-12 days: Brooker 2001) and Eastern Yellow Robin (11-13 days: Marchant 1985a; Berry 2001; Debus 2006a). The nest-predation hypothesis (Skutch 1949; Slagsvold 1982) predicts that tropical and southern temperate birds with small clutches should have shorter incubation and nestling (fledging) periods than those in northern latitudes. Geffen \& Yom-Tov (2000) found little or no difference in either incubation or nestling periods between temperate and tropical regions (although southern temperate species were not included in their analysis). However, for North American passerines, nestling periods were shorter with increased nest-predation rate, and species with higher nest-predation rates produced more broods and had smaller clutch-sizes (Martin 1995).

\section{Parental care during the incubation and nestling periods}

In our study, the mean diurnal incubation constancy for three female Jacky Winters was $69 \%$ ( $n=2150$ minutes of observation). At Moruya, NSW, the incubation constancy of a female Jacky Winter at one nest averaged $58 \%$ (range $21-86 \%, n=513$ observation min.) depending on ambient temperature (Marchant 1985b). For seven southern temperate robin species, female diurnal incubation constancy ranged from $58 \%$ to $84 \%$ depending on temperature (latitude and elevation) and habitat (Table 4). For three tropical robin species, female incubation constancy was $66 \%$ in the Grey-headed Robin in tropical upland rainforest (Frith \& Frith 2000), 54\% in the Papuan Flyrobin in montane tropical New Guinea (Donaghey 2017) and only $\sim 30 \%$ in the Lemon-bellied Flycatcher in tropical northern Australia (Noske 2011). The latitude and elevation of the tropical robin study sites ranged from $19^{\circ} \mathrm{S}, 875 \mathrm{~m}$ asl (Grey-headed Robin: Frith \& Frith 2000) and $12^{\circ} \mathrm{S}$, $<100 \mathrm{~m}$ asl (Lemon-bellied Flycatcher: Noske 2011) to $5^{\circ} \mathrm{S}, 2800 \mathrm{~m}$ asl (Papuan Flyrobin: Donaghey 2017).

In passerine birds, such as Australian robins, in which only the female incubates, there is a trade-off between

Table 4. Incubation constancy (IC) of southern temperate robins in relation to latitude, elevation and habitat.

\begin{tabular}{lcccccc}
\hline Species & IC $(\%)$ & Study site & Latitude $\left({ }^{\circ} S\right)$ & Elevation ( $m$ asl) & Habitat & Reference \\
\hline Eastern Yellow Robin & 81 & Moruya NSW & 35 & $<100$ & Eucalypt forest \& woodland & Marchant (1985a) \\
\hline Hooded Robin & 65 & Armidale NSW & 30 & $900-1100$ & Eucalypt forest & Fitri \& Ford (2003) \\
\hline Dusky Robin & 84 & Myalla TAS & 41 & 150 & Wet eucalypt forest & Higgins \& Peter (2002) \\
\hline Jacky Winter & 58 & Moruya NSW & 35 & $<100$ & Acacia woodland & Marchant (1985b) \\
\hline Jacky Winter & 69 & Gluepot SA & 33 & 57 & Mallee & This study \\
\hline Flame Robin & 78 & Nimmitabel NSW & 36 & $800-900$ & Open eucalypt forest & Robinson (1990) \\
\hline Scarlet Robin & 79 & Nimmitabel NSW & 36 & $800-900$ & Open eucalypt forest & Robinson (1990) \\
\hline Red-capped Robin & 78 & Gluepot SA & 33 & 57 & Mallee & Higgins \& Peter (2002) \\
\hline
\end{tabular}


sessions spent on the nest warming the eggs and absences off the nest to gather food. The daily number of bouts on and off the nest and the duration of bouts by the female are determined by temperature, her energy needs, food availability, and the risk of nest-predation (Conway \& Martin 2000). Compared with other Australian robins, the most striking feature of Jacky Winter incubation behaviour was the more frequent and shorter bouts on and off the nest. The mean duration of incubation on-bouts of the Jacky Winter at Moruya was 3.0 minutes (range 0.5-14.5 min., $n=87$ : Marchant 1985b), and 4.58 minutes at Gluepot (this study) compared with a mean of 13.8 minutes in the Redcapped Robin at Gluepot (Donaghey in Higgins \& Peter 2002), 21.5 minutes in the Hooded Robin around Armidale, NSW (Fitri \& Ford 2003) and 14.7 minutes in the Eastern Yellow Robin at Moruya (Marchant 1985a). In contrast, Conway \& Martin (2000) found that northern temperate passerines, in which only the female incubates, had high mean nest-attentiveness $(75 \%)$, long on-bouts (mean $38 \mathrm{~min}$.), short off-bouts (mean $10 \mathrm{~min}$.), fewer nest visits (mean 3.6 trips $/ \mathrm{h}$ ) and moderate nest-predation (mean $41 \%$ ). They suggested that the incubation behaviour of these North American passerines might have evolved more in response to nest-predation than to food availability. The high nest-predation in the Jacky Winter (Wood et al. 2008; this study) raises the question of why this species has evolved frequent nest visits, and short on- and off-bouts, all of which increase activity at the nest, and so also the risk of predation of eggs and young by avian predators. Mean duration of absences from the nest was 2.07 minutes for three incubating Jacky Winter females (this study) compared with 3.8 minutes for an incubating female Redcapped Robin at Gluepot (Donaghey in Higgins \& Peter 2002). The mean number of visits to the nest by incubating females over 12-h days was 108 for the Jacky Winter (this study), and 40 for one female Red-capped Robin (RHD unpubl. data). The female Jacky Winter's frequent short bouts off the nest to forage and solicit food from her mate to meet her energy needs is presumably a proximate response to temporal and spatial availability of invertebrate food, and possibly an ultimate response to food limitation. Chalfoun \& Martin (2007) provided experimental evidence that supplementary feeding of incubating Karoo Prinias Prinia maculosa increased nest-attentiveness from $49 \%$ to $57 \%$ which they interpreted as a proximate response to food availability.

The mean time that female Jacky Winters spent brooding over the entire nestling period was 55\% in our study, compared with $54 \%$ in the Eastern Yellow Robin (Marchant 1985a) and 33\% in the Grey-headed Robin (Frith \& Frith 2000), but apparently lower than for the Scarlet Robin (56\% for Days $1-3$ and 5\% for Days 9-16) and Flame Robin (76\% for Days $1-3$ and $10 \%$ for Days 9-16) (Robinson 1990). In our study at Gluepot, a pair of Jacky Winters provisioned their two young at a mean rate of 14.6 feeding trips per hour over the entire nestling period compared with 17.6 feeds per hour on Day 12 of the nestling period in the Red-capped Robin (RHD unpubl. data). For other robins, the mean number of feeding trips to the nest per hour was 7 (Marchant 1985a) and 6.6 (Zanette et al. 2000) in the Eastern Yellow Robin, 10 in the Hooded Robin (Fitri \& Ford 2003) and 9.7 in the Greyheaded Robin (Frith \& Frith 2000). The feeding rates of 9.3 trips/h in the Scarlet Robin and 12.1 trips/h in the Flame Robin (Robinson 1990) are lower than those for the Jacky
Winter and Red-capped Robin. Adult Flame and Scarlet Robins delivered food to nestlings at a maximum rate of 25 times per hour (8.3 feeds/h/nestling: Robinson 1990) compared with a maximum of 34 feeding trips per hour (17 feeds/h/nestling) on Day 15 of the Jacky Winter nestling period. Compared with other Australian robins, feeding rates throughout the nestling period were higher in the Jacky Winter than in all other robins except perhaps the Red-capped Robin (although sample sizes were small).

\section{Nest success, re-nesting and multiple broods}

Annual and lifetime reproductive output is determined by clutch-size, nest-predation, brood-reduction, number of broods, and longevity of adults and juveniles. Nest success of Jacky Winters at Gluepot was $22.2 \%$ (young fledged from two of nine nests). In south-eastern Queensland, 16 young hatched in eight nests and seven of these fledged from five nests ( $25 \%$ nest success); in three nests, brood-size was reduced to one (Wood et al. 2008). Jacky Winters usually build a replacement nest after failure and sometimes after success. At Greensborough, Victoria, the first three nests of a pair of Jacky Winters failed, and two young fledged from the fourth nest in December (Sharland 1929). The study by Wood et al. (2008) over one breeding season further demonstrates re-nesting: of the five pairs of Jacky Winters with young that fledged, one pair fledged two young on their first attempt then two repeat nests failed, another pair fledged one young from one nest, one pair fledged two young on their third attempt, another pair fledged one young from its second nest, and the fifth pair fledged one young on its fourth attempt. Of the three pairs that produced no young, two had three unsuccessful attempts and the third had four (deduced from Figures 1-2 in Wood et al. 2008). Keast (1994) recorded that one pair of Jacky Winters raised two broods in a season: two young fledged from the first nest on 11 October, a second brood fledged on 5 December, and the re-nesting interval was at least 15 days. The fledglings from the first brood were dependent on the adults for 10-15 days, and the second brood stayed with the adults for at least 3 weeks (Keast 1994).

\section{Nest-predation and anti-predator behaviour of adults and young}

Nest-predation is the primary cause of reproductive failure in songbirds in Australia and globally (Ricklefs 1969; Robinson et al. 2000; Ford et al. 2001; McLean et al. 2005; Debus 2006c; Thompson 2007; Remeš et al. 2012). High nestling mortality should select for shorter nestling periods, nest concealment, accelerated growth and development of young, anti-predator behaviour of young and adults, less nest visitation, and re-nesting and multiple broods. Although the mean total number of nest visits of $19 / \mathrm{h}$ by pairs of Jacky Winters was almost double that during the incubation period (10.6 nest visits/h), four nests failed during the egg stage and five failed during the nestling stage in the present study. However, in south-eastern Queensland, 12 of 20 nests with eggs failed and three with young failed (deduced from Figure 2 in Wood et al. 2008) even though nest visits are more frequent during the nestling period.

Roper \& Goldstein (1997) tested the Skutch hypothesis, that activity at the nest increases the risk of predation, 
in tropical birds. They found that predation at nests of the Black-crowned Antshrike (formerly Western Slaty Antshrike) Thamnophilus atrinucha (Thamnophilidae) did not increase during the nestling stage even though nest visitation was far higher than during the incubation phase. Martin et al. (2000) tested the effect of nest-site quality on nest-predation particularly during the incubation stage, and discovered that, although actual nest-predation was no greater during the nestling stage, there was a greater daily risk of nest-predation during the incubation stage because of nests in poor sites. When they removed these poor-quality nest-sites from their analysis, they found that more nests were depredated during the nestling stage when parental activity was greatest. Thus nest-site quality coupled with high nest visitation may help explain the high failure of Jacky Winter nests during incubation.

Our study identified the Collared Sparrowhawk and Grey Currawong as potential nest-predators based on predator-avoidance behaviour by Jacky Winters. Other potential predators of Jacky Winter eggs and young at Gluepot include the Australian Raven (a known predator of Southern Scrub-robin eggs: Donaghey in Higgins \& Peter 2002), Grey Shrike-thrush and Grey Butcherbird Cracticus torquatus (Major et al. 1999). In the present study, we observed nesting Jacky Winters defending the nest area by attacking and expelling Yellow-plumed Honeyeaters and ground-foraging Crested Bellbirds. In the Hooded Robin, Fitri \& Ford (1998) also reported aggression toward ground-foraging birds (Jacky Winter and Willie Wagtail Rhipidura leucophrys), and also nectar-foraging Ptilotula honeyeaters, such as Fuscous $P$. fusca and White-plumed Honeyeaters $P$. penicillata. Interspecific aggression by nesting, ground-foraging robins might be directed at other ground-foraging birds, which occupy a similar niche and might compete for similar food (Fitri \& Ford 1998). Ley et al. (1997) recorded that Fuscous and White-plumed Honeyeaters steal nest material from active nests of other honeyeaters and the Eastern Yellow Robin. In southwestern Australia, Fulton (2006) confirmed with cameras that the Yellow-plumed Honeyeater engages in eggpredation and steals nest materials from open-cup nests. At Dryandra Woodland, Western Australia, we observed Yellow-plumed Honeyeaters stealing nest material from an active nest of a Western Yellow Robin Eopsaltria griseogularis with two young (RHD unpubl. data). These observations suggest that Jacky Winters defend their nests from honeyeaters that steal nest material and disrupt nesting activities.

Our observations of the cryptic posture of Jacky Winter nestlings, sitting upright with bills pointing upward, together with their cryptic mottled juvenile plumage, suggest that these traits have evolved as camouflage against diurnal avian predators. Similar behaviour and plumage have been reported in Lemon-bellied Flycatcher nestlings by Harvey \& Harvey (1919) and Noske (2011).

\section{Nest type, placement and concealment}

Nest type and size, degree of camouflage, and nest placement all contribute to nest concealment from predators. The two Microeca species that occur in more open habitats (Jacky Winter and Lemon-bellied Flycatcher) are similar in body size and in their use of nest materials, and both place their nests on exposed dead branches
(Higgins \& Peter 2002). In the present study, the two Jacky Winter nests where young fledged were $4.09 \mathrm{~m}$ and $2.74 \mathrm{~m}$ above the ground, had live branches and foliage $>60 \mathrm{~cm}$ above the nest, and the nest-trees were situated at the edge of a more open area with low shrubs east and north of the nest. Thus sitting females at the successful nests had a more elevated, expansive view of their surroundings (cf. Götmark et al. 1995). The Leaden Flycatcher Myiagra rubecula (length $15 \mathrm{~cm}$, mass $12 \mathrm{~g}$ ) is a small, arboreal, insectivorous monarch flycatcher (Monarchidae) with similar foraging and breeding lifehistory traits to the Jacky Winter. It inhabits woodlands of eastern Australia, forages by sally-snatching from foliage and by flush-pursuit, builds an open-cup nest on an exposed horizontal dead branch below a live branch, has low $(23 \%)$ nest success despite repelling larger intruders from its nest area and has repeated nesting attempts after failure (Trémont \& Ford 2000; Higgins et al. 2006). The literature is ambivalent about the influence of nestsite selection and concealment from predators in relation to avian breeding success. Some studies of Northern Hemisphere open-cup-nesting passerines (Martin \& Roper 1988; Kelly 1993; Weidinger 2002) lend support to the nest-concealment hypothesis that less exposure reduces predation, whereas other studies (Wilson \& Cooper 1998; Braden 1999) consider that nest-predation is random and operates at larger scales than the nest-site. Martin (1993) used real and artificial nests to simulate the coexistence of four species that used the same or different nest-sites to test the hypothesis that predation favours differences in nest-sites. Nest-density and predation increased when coexisting species used similar nest-sites, suggesting that predators develop a search image for specific nest-sites rather than search randomly (Martin 1993). Comparisons between coexisting robin species can yield significant differences in the effect of micro- and macrohabitat on breeding success (Debus 2006d). Breeding Eastern Yellow Robins selected a macrohabitat of mainly moist gullies and lower slopes, whereas breeding Scarlet Robins mainly occupied ridges and upper slopes. Eastern Yellow Robin breeding territories had denser lower storey and more eucalypt saplings and shrubs than did Scarlet Robin territories (Debus 2006d). The greater breeding success of Eastern Yellow Robins was positively related to greater shrub foliage cover and density around the nest, compared with the more open macrohabitat and more exposed nestsite of the Scarlet Robin. Furthermore, the two Eastern Yellow Robin territories with the highest habitat complexity and cover scores also produced more fledglings and recruits (Table 6 in Debus 2006d).

Four resident coexisting robin species at Gluepot Reserve partitioned their habitat for territories and nestsites. In Jacky Winters that nested in more exposed sites, the nest success of $22.2 \%$ was less than half of that in the ground-nesting Southern Scrub-robin (50\% in 2001, $n=5 ; 58.8 \%$ in 2002, $n=17$ ) and in the Red-capped Robin $(64.7 \%, n=17)$ and Hooded Robin $(66.7 \%, n=3)$, which mostly built nests at low to medium heights in relatively dense foliage with good concealment (RHD unpubl. data).

\section{Post-fledging care}

The duration that fledglings are dependent on parental care (post-fledging period) may help to explain life-history variation between latitudes. Our study at Gluepot ceased 
soon after the Jacky Winters fledged, so we were unable to determine the length of post-fledging dependence. Wood et al. (2008) determined that one juvenile Jacky Winter was dependent on the adults for $c .9$ weeks, and was fed mostly by the male while the female incubated eggs in a replacement nest. In the tropical Lemon-bellied Flycatcher, the post-fledging period was at least 7 weeks (Noske 2011). In the Petroicidae, the post-fledging period was $<20$ days in one species, $20-40$ days in six species, and $>40$ days in another species (Russell 2000). We gathered more recent data for 16 species of Petroicidae from the literature and, with our observations, found that the post-fledging dependence period was $20-40$ days in ten species, 40-60 days in four species, and $>60$ days in two species (Frith \& Frith 2000; Higgins \& Peter 2002; Dowling 2003; Fitri \& Ford 2003; Powys 2004; Russell et al. 2004a; Debus 2006a; Wood et al. 2008; Noske 2011; RHD unpubl. data). For two pairs of Western Yellow Robins at Dryandra Woodland, the post-fledging period was $>21$ days, and one group of four Western Yellow Robins fed two fledglings on the ground for 20 days (RHD pers. obs.), thus the postfledging period could be at least 30 days, similar to that in the Eastern Yellow Robin. Russell (2000) showed that most northern temperate bird species were independent in $<20$ days, whereas most southern temperate and tropical birds were independent in 20-60 days. Thus the postfledging period of 20-60 days in most robin species corresponds with that in southern temperate and tropical birds. Russell et al. (2004b) assembled a large database to conduct a comprehensive comparative analysis and, after controlling for phylogeny, found that extended parental care was widespread among passerines and significantly longer in tropical and Southern Hemisphere birds than in Northern Hemisphere birds. The relevance of extended parental care of fewer young in Southern Hemisphere and tropical birds is that it is considered to be a parental investment that contributes to higher juvenile and adult survival (Russell 2000; Russell et al. 2004b; Tarwater \& Brawn 2010).

\section{Survival of adults}

Rowley \& Russell (1991) compared annual survival in northern and southern temperate bird species and found that an annual survival greater than $70 \%$ was much more prevalent in Australia than in North America and Europe. For example, based on recapture rates of four species of resident small passerines in south-western Australia, the mean annual survival was $73.5 \%$ (range $67-78 \%$ ), and maximum longevity was $>10$ years (Brown et al. 1990).

Annual survival is high in the White-breasted Robin (males 86\%, females 79\%: Russell et al. 2004a) and Eastern Yellow Robin (71\%: Debus 2006b). There are few survival data for tropical Australian robins, but sedentary, small-bodied White-faced Robins at Iron Range National Park, Cape York Peninsula, Queensland, have an annual adult survival rate of $75 \%$ and individuals may live up to 18 years (Coleman et al. 2012; Rawsthorne \& Donaghey 2012). The tropical Lemon-bellied Flycatcher $(12 \mathrm{~g})$ also has a high longevity of at least 13.5 years (Noske 2011). There are few survival data for Jacky Winters, but the maximum longevity recorded is 5 years 3.7 months (Australian Bird and Bat Banding Scheme http://www.environment.gov.au/ topics/science-and-research/bird-and-bat-banding-data/ search-abbbs-database, retrieved 30 June 2017).

\section{Breeding strategy}

Australian robins build open-cup-shaped nests and have a suite of life-history traits such as moderately long breeding seasons, small clutch-sizes, low reproductive rates, high nest failure, multiple broods, lower nest-attentiveness, extended post-fledging care and high adult survival and longevity that are opposite to those of northern temperate songbirds and more similar to a slow pace of life exhibited by tropical passerines (Russell 2000; Russell et al. 2004a,b; Robinson et al. 2010). More recently, Martin (2015) sought to explain latitudinal variation in avian lifehistory traits by comparing nestling growth rates, parental effort and mortality in temperate and tropical songbirds. He discovered that tropical birds have slower peak growth but faster subsequent growth so grow wings faster than temperate birds, thus enabling tropical fledglings to escape and evade predators and reduce mortality risk. The small clutch-sizes of tropical birds allow adults to increase fooddelivery rates per young and reduce mortality risk to adults and juveniles (Martin 2015). There are insufficient data on nestling growth and development, and adult and juvenile mortality, to substantiate Martin's findings for temperate and tropical Australasian robins.

The Jacky Winter has a high rate of nest-predation, builds a small nest, has a small clutch-size, and the nestlings adopt anti-predator postures, suggesting that these traits evolved in response to a high risk of nest-predation. Its parental-care strategy is also characterised by moderate nest-attentiveness and a higher number of on- and offbouts during incubation, a moderately long nestling period, and a higher number of total nest visits and feeding trips during the nestling phase than in any other robin species. These traits are not consistent with nest-predation theory and suggest different selection pressure(s) or trade-off(s). Some traits, such as frequent short bouts on and off the nest, male incubation feeding, asynchronous hatching, brood-reduction and nestling starvation, suggest proximate behavioural responses to food availability, and an ultimate response to food limitation. The breeding strategy of frequent short bouts on and off the nest by female Jacky Winters coupled with high rates of male incubation feeding appears to have evolved to meet the energy needs of the female and her young in response to the temporal and spatial availability of invertebrate prey. We postulate that annual productivity in the Jacky Winter is constrained mostly by high nest-predation because of exposed nests and high nest visitation rates but also by food availability, and is counteracted by frequent replacement nests and an extended breeding season. Future research could include the spatial dispersal of breeding Jacky Winters in relation to habitat and social behaviour; temporal variation in food availability; growth and development of nestlings, asynchronous hatching and brood-reduction; causes of nest failure and identity of nest-predators; dispersal, survival and recruitment of juveniles; and annual and lifetime reproductive effort.

\section{Acknowledgements}

We dedicate this paper to the memory of deceased Gluepot volunteers Michael Hyde, Dexter and Irena Palmer and Pat Fairclough. We are most grateful to David Baker-Gabb and Duncan Mackenzie for granting permission to do research at Gluepot Reserve and for facilitating bird banding. RHD thanks David Drynan of the Australian Bird and Bat Banding Scheme for 
re-instating his banding authority and approving his projects. We thank Jenny Rolfe, Susan Robertson, Alan Robertson and Bianca Weir, who helped find nests and conduct watches of Jacky Winter nests at Gluepot in 2001. We are very grateful to Con Rhee for computing the two linear regression graphs. Many thanks go to reviewers Stephen Debus, Harry Recher and David Watson and editors James Fitzsimons and Julia Hurley for their meticulous reviews and thorough editing which greatly improved this paper.

\section{References}

Antos, M.J. \& Bennett, A.F. (2006). Foraging ecology of groundfeeding woodland birds in temperate woodlands of southern Australia. Emu 106, 29-40.

Barrett, G.W., Silcocks, A., Barry, S., Cunningham, R. \& Poulter, R. (2003). The New Atlas of Australian Birds. Royal Australasian Onithologists Union, Melbourne.

Beehler, B.M. \& Pratt, T.K. (2016). Birds of New Guinea: Distribution, Taxonomy, and Systematics. Princeton University Press, Princeton, New Jersey, USA.

Bell, H.L. (1982). A bird community of lowland rain forest in New Guinea. 2. Seasonality. Emu 82, 65-74.

Berry, L. (2001). Breeding biology and nesting success of the Eastern Yellow Robin and the New Holland Honeyeater in a southern Victorian woodland. Emu 101, 191-197.

Boles, W.E. (2007). Family Petroicidae (Australasian robins). In: del Hoyo, J., Elliot, A. \& Christie, D.A. (Eds). Handbook of the Birds of the World, Volume 12: Picathartes to Tits and Chickadees, pp. 438-488. Lynx Edicions, Barcelona, Spain.

Braden, G.T. (1999). Does nest placement affect the fate or productivity of California Gnatcatcher nests? Auk 116, 984-993.

Brooker, B. (2001). Biology of the Southern Scrub-robin (Drymodes brunneopygia) at Peron Peninsula, Western Australia. Emu 101, 181-190.

Brooker, M.I.H. \& Kleinig, D.A. (2001). Field Guide to Eucalypts, Volume 2: South-western and Southern Australia. Bloomings Books, Melbourne.

Brown, R.J., Brown, M.N. \& Russell, E.M. (1990). Survival of four species of passerine in karri forests in southwestern Australia. Corella 14, 69-78.

Chalfoun, A.D \& Martin, T.E. (2007). Latitudinal variation in avian incubation attentiveness and a test of the food limitation hypothesis. Animal Behaviour 73, 579-585.

Chippendale, G.M. (1988). Flora of Australia, Volume 19: Myrtaceae - Eucalyptus, Angophora. Australian Government Printing Service, Canberra.

Christidis, L. \& Boles, W.E. (2008). Systematics and Taxonomy of Australian Birds. CSIRO Publishing, Melbourne.

Christidis, L., Irestedt, M., Rowe, D., Boles, W.E. \& Norman, J.A. (2011). Mitochondrial and nuclear DNA phylogenies reveal a complex evolutionary history in the Australasian robins (Passeriformes: Petroicidae). Molecular Phylogenetics and Evolution 61, 726-738.

Coates, B.J. (1990). The Birds of Papua New Guinea, Volume II: Passerines. Dove Publications, Brisbane.

Coleman, J.T., van Gessel, F.W. \& Clayton, M. (2012). Longevity and movements in the White-faced Robin (Tregellasia leucops albigularis) in Iron Range National Park, Cape York. Sunbird 42, 11-23.

Conway, C.J. \& Martin, T.E. (2000). Evolution of passerine incubation behavior: Influence of food, temperature, and nest predation. Evolution 54, 670-685.

Debus, S.J.S. (2006a). Breeding biology and behaviour of the Scarlet Robin Petroica multicolor and Eastern Yellow Robin Eopsaltria australis in remnant woodland near Armidale, New South Wales. Corella 30, 59-65.

Debus, S.J.S. (2006b). Breeding and population parameters of robins in a woodland remnant in northern New South Wales, Australia. Emu 106, 147-156.
Debus, S.J.S. (2006c). The role of intense nest predation in the decline of Scarlet Robins and Eastern Yellow Robins in remnant woodland near Armidale, New South Wales. Pacific Conservation Biology 12, 279-287.

Debus, S.J.S. (2006d). Breeding-habitat and nest-site characteristics of Scarlet Robins and Eastern Yellow Robins near Armidale, New South Wales. Pacific Conservation Biology 12, 261-271.

Debus, S.J.S. (2013). Breeding of the Hooded Robin Melanodryas cucullata in native and exotic woodlands near Armidale, New South Wales. Corella 37, 49-56.

Donaghey, R.H. (2015). Nest and egg of the Dimorphic Fantail Rhipidura brachyrhyncha and a review of clutch-sizes in New Guinean passerines. Australian Field Ornithology 32, 69-86.

Donaghey, R.H. (2017). Observations of nesting in the Papuan Flyrobin and the Olive Flyrobin, and post-fledging care in the Torrent Flycatcher, all endemic to New Guinea. Australian Field Ornithology 34, 111-115.

Dowling, D.K. (2003). Breeding biology of the Red-capped Robin. Australian Journal of Zoology 51, 533-549.

Emison, W.B. \& Bren, W.M. (1989). Common birds of the mallee region of northwestern Victoria. In: Noble, J.C. \& Bradstock, R.A. (Eds). Mediterranean Landscapes in Australia: Mallee Ecosystems and their Management, pp. 221-242. CSIRO, Melbourne.

Fitri, L.L. \& Ford, H.A. (1998). Aggression among Hooded Robins Melanodryas cucullata and other birds. Corella 22, 24-29.

Fitri, L. \& Ford, H.A. (2003). Breeding biology of Hooded Robins Melanodryas cucullata in New England, New South Wales. Corella 27, 68-74.

Ford, H.A. (2011). The causes of decline in birds of eucalypt woodlands: Advances in our knowledge over the last 10 years. Emu 111, 1-9.

Ford, H.A., Barrett, G.W., Saunders, D.A. \& Recher, H.F. (2001). Why have birds in the woodlands of southern Australia declined? Biological Conservation 97, 71-88.

Frith, D.W. \& Frith, C.B. (2000). The nesting biology of the Greyheaded Robin Heteromyias albispecularis (Petroicidae) in Australian upland tropical rainforest. Emu 100, 81-94.

Fulton, G.R. (2006). Identification of nest predators with remote cameras and artificial nests in extensive old-growth woodland of south-western Australia. Corella 30, 35-39.

Geffen, E. \& Yom-Tov, Y. (2000). Are incubation and fledging periods longer in the tropics? Journal of Animal Ecology 69, 59-73.

Gill, F. \& Donsker, D. (Eds) (2017). IOC World Bird List (v. 7.1). Available online: http://www.worldbirdnames.org (retrieved 7 February 2017).

Götmark, F., Blomqvist, D., Johansson, O.C. \& Bergkvist, J. (1995). Nest site selection: A trade-off between concealment and view of surroundings. Journal of Avian Biology 26, 305-312.

Harvey, W.G. \& Harvey, R.C. (1919). Bird notes from Mackay, Q. Emu 19, 34-42.

Higgins, P.J. \& Peter, J.M. (Eds) (2002). Handbook of Australian, New Zealand \& Antarctic Birds, Volume 6: Pardalotes to Shrike-thrushes. Oxford University Press, Melbourne.

Higgins, P.J., Peter, J.M. \& Cowling, S.J. (Eds) (2006). Handbook of Australian, New Zealand \& Antarctic Birds, Volume 7: Boatbill to Starlings. Oxford University Press, Melbourne.

Hyde, M. (2001). The Vegetation of Birds Australia Gluepot Reserve: Northern Murray Mallee, South Australia. Wallowa Mallee Research Books, Blackwood, SA.

Jetz, W., Sekercioglu, C.H. \& Böhning-Gaese, K. (2008). The worldwide variation in avian clutch size across species and space. PLoS Biology 6, 2650-2657.

Keast, A. (1994). The annual cycle in a vocalisation context: A comparison of the Eastern Yellow Robin Eopsaltria australis and Jacky Winter Microeca leucophaea. Emu 94, 230-238.

Kelly, J.P. (1993). The effect of nest predation on habitat selection by Dusky Flycatchers in Limber Pine-Juniper woodland. Condor 95, 83-93. 
Ley, A.J., Oliver, D.L. \& Williams, M.B. (1997). Theft of nesting material involving honeyeaters (Meliphagidae). Corella 21, $119-123$

Loynes, K., Joseph, L. \& Keogh, J.S. (2009). Multi-locus phylogeny clarifies the systematics of the Australo-Papuan robins (Family Petroicidae, Passeriformes). Molecular Phylogenetics and Evolution 53, 212-219.

Mackenzie, D. \& Fitzsimons, J. (2013). From Danggali to Riverland: Experiences from the Bookmark Biosphere Reserve, South Australia. In: Fitzsimons, J., Pulsford, I. \& Westcott, G. (Eds). Linking Australia's Landscapes: Lessons and Opportunities from Large-scale Conservation Networks, pp. 65-74. CSIRO Publishing, Melbourne.

Major, R.E., Christie, F.J., Gowing, G. \& Ivison, T. (1999). Elevated rates of predation on artificial nests in linear strips of habitat. Journal of Field Ornithology 70, 351-364.

Marchant, S. (1985a). Breeding of the Eastern Yellow Robin Eopsaltria australis. In: Keast, A., Recher, H., Ford, H. \& Saunders, D. (Eds). Birds of Eucalypt Forests and Woodlands: Ecology, Conservation, Management, pp. 231-240. Royal Australasian Ornithologists Union and Surrey Beatty \& Sons, Sydney.

Marchant, S. (1985b). Nesting of the Jacky Winter. Australian Birds 20, 22-24.

Martin, T.E. (1993). Nest predation and nest sites: New perspectives on old patterns. BioScience 43, 523-532.

Martin, T.E. (1995). Avian life history evolution in relation to nest sites, nest predation, and food. Ecological Monographs 65, 101-127.

Martin, T.E. (2015). Age-related mortality explains life history strategies of tropical and temperate songbirds. Science 349, 966-970.

Martin, T.E. \& Roper, J.J. (1988). Nest predation and nest-site selection of a western population of the Hermit Thrush. Condor 90, 51-57.

Martin, T.E., Scott, J. \& Menge, C. (2000). Nest predation increases with parental activity: Separating nest site and parental activity effects. Proceedings of the Royal Society of London, Series B, Biological Sciences 267, 2287-2293.

McLean, I.G., Recher, H.F., Studholme, B.J.S., Given, A. \& Duncan, C. (2005). Breeding success and timing of nesting by forest birds on the Northern Tablelands of New South Wales, Australia. Corella 29, 53-62.

Noske, R. (2011). Lemon-essence. Wingspan 21 (4), 36-39.

Noske, R.A. \& Franklin, D.C. (1999). Breeding seasons of land birds in the Australian monsoon tropics: Diverse responses to a highly seasonal environment. Australian Biologist 12, 72-90.

Olsen, P., Weston, M., Tzaros, C. \& Silcocks, A. (2005). The state of Australia's birds 2005: Woodlands and birds. Wingspan 15 (Supplement), 1-32.

Powys, V. (2004). Breeding biology of the Red-capped Robin Petroica goodenovii in Capertee Valley, New South Wales. Corella 28, 4-10.

Rawsthorne, J. \& Donaghey, R. (2012). Dancing clowns: Display behaviour between two White-faced Robins Tregellasia leucops. Australian Field Ornithology 29, 182-188.

Recher, H.F. \& Davis, W.E. Jr (1998). The foraging profile of a wandoo woodland avifauna in early spring. Australian Journal of Ecology 23, 514-527.

Recher, H.F. \& Davis, W.E. Jr (2014). Responses of birds to episodic summer rainfall in the Great Western Woodlands, Western Australia. Australian Zoologist 37, 206-218.

Recher, H.F., Davis, W.E. \& Calver, M.C. (2002). Comparative foraging ecology of five species of ground-pouncing birds in Western Australian woodlands with comments on species decline. Ornithological Science 1, 29-40.

Remeš, V., Matysioková, B. \& Cockburn, A. (2012). Long-term and large-scale analyses of nest predation patterns in Australian songbirds and a global comparison of nest predation rates. Journal of Avian Biology 43, 435-444.

Ricklefs, R.E. (1966). The temporal component of diversity among species of birds. Evolution 20, 235-242.
Ricklefs, R.E. (1969). An analysis of nesting mortality in birds. Smithsonian Contributions to Zoology 9, 1-48.

Robinson, D. (1990). The nesting ecology of sympatric Scarlet Robin Petroica multicolor and Flame Robin P. phoenicea populations in open eucalypt forest. Emu 90, 40-52.

Robinson, W.D., Hau, M., Klasing, K.C., Wikelski, M., Brawn, J.D., Austin, S.H., Tarwater, C.E. \& Ricklefs, R.E. (2010). Diversification of life histories in New World birds. Auk 127 253-262.

Robinson, W.D., Robinson, T.R., Robinson, S.K. \& Brawn, J.D. (2000). Nesting success of understorey forest birds in central Panama. Journal of Avian Biology 31, 151-164.

Roper, J.J. \& Goldstein, R.R. (1997). A test of the Skutch hypothesis: Does activity at nests increase nest predation risk? Journal of Avian Biology 28, 111-116.

Rowley, I. \& Russell, E. (1991). Demography of passerines in the temperate southern hemisphere. In: Perrins, C.M., Lebreton, J.-D. \& Hirons, G.J.M. (Eds). Bird Population Studies. Relevance to Conservation and Management, pp. 22-44. Oxford University Press, Oxford, UK.

Russell, E.M. (2000). Avian life histories: Is extended parental care the southern secret? Emu 100, 377-399.

Russell, E.M., Brown, R.J. \& Brown, M.N. (2004a). Life history of the White-breasted Robin, Eopsaltria georgiana (Petroicidae), in south-western Australia. Australian Journal of Zoology 52, $111-145$

Russell, E.M., Yom-Tov, Y. \& Geffen, E. (2004b). Extended parental care and delayed dispersal: Northern, tropical, and southern passerines compared. Behavioral Ecology 15, 831-838.

Sharland, M.S.R. (1929). Nesting oddities. Emu 29, 85-89.

Skutch, A.F. (1949). Do tropical birds rear as many young as they can nourish? Ibis 91, 430-455.

Slagsvold, T. (1982). Clutch size variation in passerine birds: The nest predation hypothesis. Oecologia 54, 159-169.

Stevens, H.C. \& Watson, D.M. (2013). Reduced rainfall explains avian declines in an unfragmented landscape: Incremental steps toward an empty forest? Emu 113, 112-121.

Tarwater, C.E. \& Brawn, J.D. (2010). The post-fledging period in a tropical bird: Patterns of parental care and survival. Journal of Avian Biology 41, 479-487.

Taylor, S.G. (2008). Leaf litter invertebrate assemblages in boxironbark forest: Composition, size and seasonal variation in biomass. Victorian Naturalist 125, 19-27.

Thompson, F.R. III (2007). Factors affecting nest predation on forest songbirds in North America. Ibis 149 (Supplement 2), 98-109.

Trémont, S. \& Ford, H.A. (2000). Partitioning of parental care in the Leaden Flycatcher. Emu 100, 1-11.

Watson, D.M. (2011). A productivity-based explanation for woodland bird declines: Poorer soils yield less food. Emu 111, $10-18$.

Weidinger, K. (2002). Interactive effects of concealment, parental behaviour and predators on the survival of open passerine nests. Journal of Animal Ecology 71, 424-437.

Wilson, R.R. \& Cooper, R.J. (1998). Acadian Flycatcher nest placement: Does placement influence reproductive success? Condor 100, 673-679.

Wood, K.A., Thompson, N. \& Ley, A.J. (2008). Breeding territories and breeding success of the Jacky Winter Microeca fascinans in south-eastern Queensland. Australian Field Ornithology 25, 121-131.

Wyndham, E. (1986). Length of birds' breeding seasons. American Naturalist 128, 155-164.

Zanette, L. (2000). Fragment size and the demography of an areasensitive songbird. Journal of Animal Ecology 69, 458-470.

Zanette, L., Doyle, P. \& Trémont, S.M. (2000). Food shortage in small fragments: Evidence from an area-sensitive passerine. Ecology 81, 1654-1666.

Received 8 March 2017, accepted 9 July 2017, published online 4 October 2017 


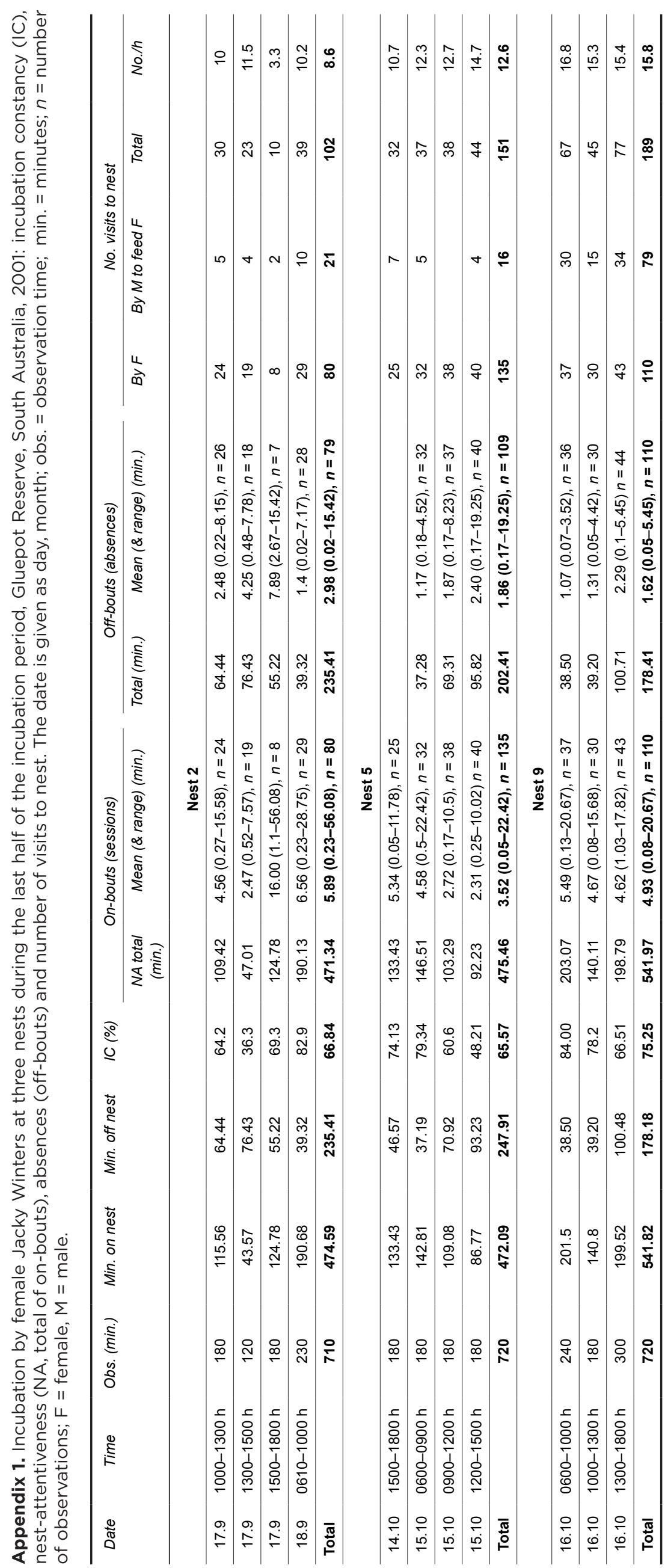




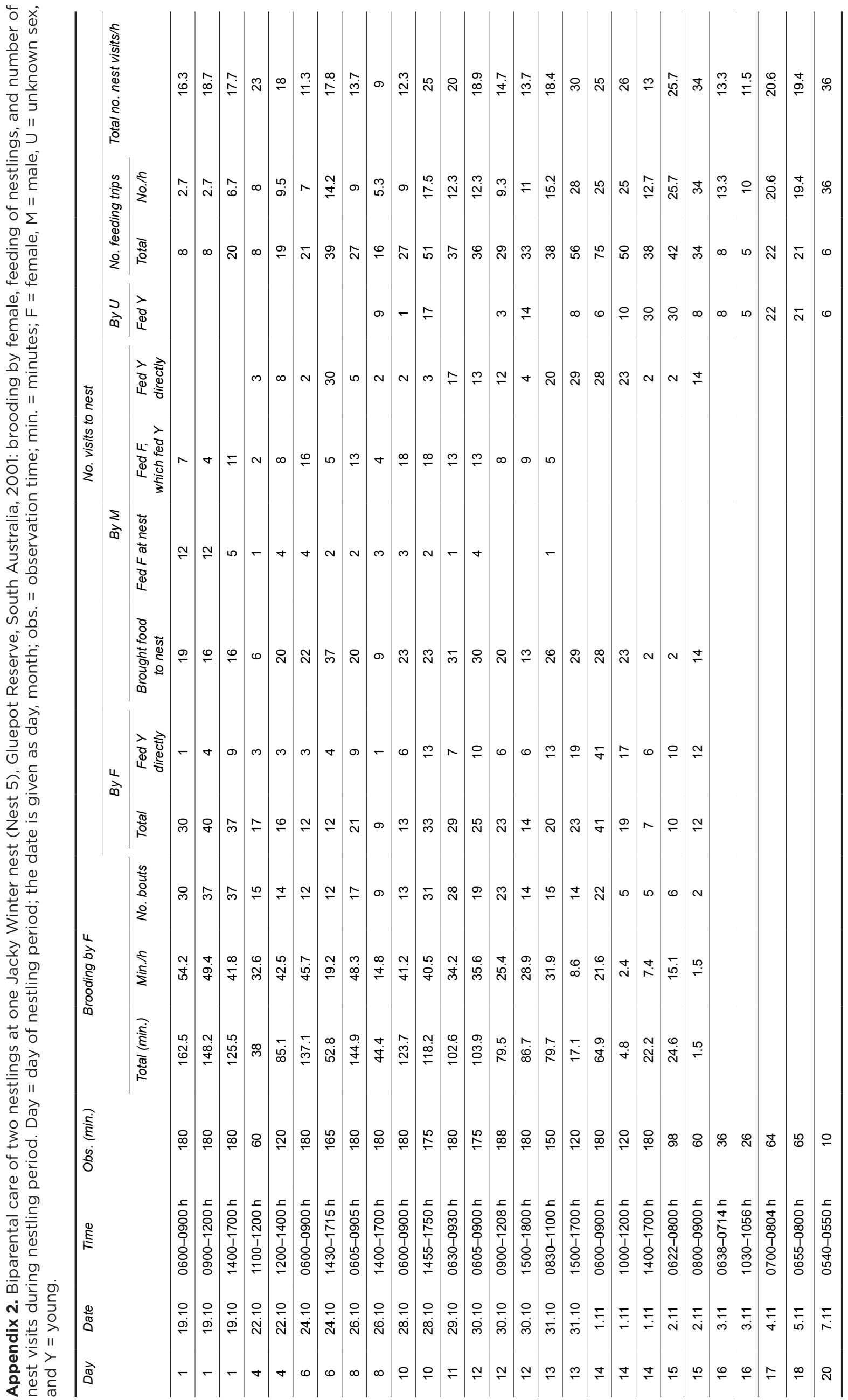

